\title{
A BOUND FOR A DETERMINANT WITH DOMINANT MAIN DIAGONAL
}

\author{
J. L. BRENNER
}

In [3, pp. 13-14], Hadamard proved that if a square matrix

$$
\left(a_{i j}\right)_{1 \leqq i, j \leqq n}
$$

satisfies the inequalities

$$
\begin{aligned}
a_{i i} & \neq 0, \\
\sigma_{i}\left|a_{k k}\right| & =\sum_{j \neq i}\left|a_{i j}\right|, 0 \leqq \sigma_{i}<1 \quad(i=1,2, \cdots, n),
\end{aligned}
$$

then the determinant of the matrix is different from 0 . Upper and lower bounds have been given for the determinant of the matrix; see $[4 ; 5 ; 6 ; 7] .{ }^{1}$ In this article, improvements are given to the bounds of $[5 ; 6]$. It is remarkable that the bound of [5] could be improved by using nothing more complicated than ratios already introduced in that article: the bound for $|\operatorname{det} A|-\left|a_{11} \cdots a_{n n}\right|$ given there was asymptotically of the correct order in the $l_{j}$ and $r_{j}$. It is possible to improve the bounds of [1a] by the methods here given.

Certain generalizations of the present results appear in [1b]. Generalizations of some lemmas in [5] will appear elsewhere.

The following lemma is needed.

Lemma. Let $A=\left(a_{i j}\right)_{1 \leqq i, j \leqq n}$ be a matrix such that the relations (1) hold. Let $b_{i j}$ be defined as $a_{i j}-a_{i 1} a_{1 j} / a_{11}$. Then $\left(b_{i j}\right)_{2 \leqq i, j \leqq n}$ has dominant main diagonal, and indeed the relations

$$
\begin{aligned}
\sigma_{i}\left|b_{i i}\right| & \geqq \sum_{j>1 ; j \neq i}\left|b_{i j}\right|, \\
b_{i i} & \neq 0
\end{aligned}
$$

hold for $i=2,3, \cdots, n$.

This lemma states that the constant $\sigma_{i}^{\prime}$ defined by the relation $\sigma_{i}^{\prime}\left|b_{i i}\right|=\sum_{j>1 ; j \neq i}\left|b_{i j}\right|$ is no greater than the corresponding constant $\sigma_{i}$. The fact that det $\left(b_{i j}\right)$ is not 0 is established in [2].

Proof. The asserted inequalities follow from the hypotheses as follows.

Presented to the Society, May 1, 1954; received by the editors December 28, 1953.

${ }^{1}$ References $1 \mathrm{a}, 1 \mathrm{~b}, 6,7$ and 2 added subsequently. The author wishes to thank the referee for calling his attention to the last. 


$$
\begin{aligned}
\sigma_{i}\left|b_{i i}\right| & \geqq \sigma_{i}\left|a_{i i}\right|-\sigma_{i}\left|a_{i 1} a_{1 i} / a_{11}\right| \\
& \geqq \sum_{j>1 ; j \neq i}\left|a_{1 j}\right|+\left|a_{i 1} / a_{11}\right|\left(\left|a_{11}\right|-\sigma_{i}\left|a_{1 i}\right|\right) \\
& \geqq \sum_{j>1 ; j \neq i}\left|a_{i j}\right|+\left|a_{i 1} / a_{11}\right|\left(\sum_{j>1 ; j \neq i}\left|a_{1 j}\right|+\left|a_{1 i}\right|\left(1-\sigma_{i}\right)\right) \\
& \geqq \sum_{i>1 ; j \neq i}\left|b_{i j}\right| . \text { Similarly, }\left|b_{i i}\right|>\sum_{j>1 ; j \neq i}\left|b_{i j}\right| .
\end{aligned}
$$

Theorem 1. Let $A=\left(a_{i j}\right)_{1 \leqq i, j \leqq n}$ be a square matrix satisfying (1). Then a bound for $\operatorname{det} A$ is

$$
|\operatorname{det} A| \geqq\left|a_{11}\right| \prod_{i>1}\left(\left|a_{i i}\right|-l_{i}+L_{i}\right),
$$

where $l_{i}$ is $\sum_{j<i} \sigma_{j}\left|a_{i j}\right| ; L_{i}$ is $\left|a_{i 1} / a_{11}\right| \sum_{j>i}\left|a_{i j}\right|$. Thus $\left|a_{i i}\right|-l_{i}$ is automatically positive, and $L_{i}$ is non-negative.

In both [5] and [6], a similar bound appears with $L_{i}$ replaced by zero. Leaving this aside, the factor $a_{i i}-l_{i}$ is still an improvement over the corresponding factor in [6], where $l_{i}$ is replaced by the sum $\sum_{j<i}\left|a_{i j}\right|$, and is also an improvement over the corresponding factor in [5], where $l_{i}$ is replaced by $\sigma_{t} \sum_{j<i}\left|a_{i j}\right|, \sigma_{t}$ being the greatest of the $\sigma_{j}$ with $j$ not equal to $i$. Even in this form, the statement can be improved to read that $\sigma_{t}$ is the greatest of the $\sigma_{j}$ with $j$ less than $i$.

This theorem is a special case of

Theorem 2. Let $A=\left(a_{i j}\right)_{1 \leqq i, j \leqq n}$ be a matrix such that relations (1) hold. $A$ bound for $|\operatorname{det} A|$ is given by the relation

(2) $|\operatorname{det} A| \geqq \prod_{j<k}\left(\left|a_{i j}\right|-r_{j}+R_{j}\right) \cdot\left|a_{k k}\right| \cdot \prod_{j>k}\left(\left|a_{j j}\right|-l_{j}+L_{j}\right)$,

where $r_{j}, l_{j}, R_{j}, L_{j}$ are defined by the relations

$$
\begin{aligned}
r_{j} & =\sum_{t>j} \sigma_{t}\left|a_{j t}\right|, & L_{j} & =\left|a_{j k} / a_{k k}\right|\left(\sum_{t>j}\left|a_{k t}\right|+\sum_{t<k}\left|a_{k t}\right|\right), \\
R_{j} & =\left|a_{j k} / a_{k k}\right| \sum_{t<j}\left|a_{k t}\right|, & l_{i} & =\sum_{k \leqq t<j} \sigma_{t}\left|a_{i t}\right|,
\end{aligned}
$$

so that $R_{j}$ and $L_{j}$ are non-negative.

To prove Theorem 2 , first reduce to 0 the nondiagonal elements of the $k$ th row of $A$ by adding an appropriate multiple of the $k$ th column to the other columns. In the resulting matrix, call $B$ the submatrix obtained by leaving out the $k$ th row and the $k$ th column. The $(i, j)$ element $b_{i j}$ of $B$ is $a_{i j}-a_{k j} a_{i k} / a_{k k}(i \neq k, j \neq k)$. As an induc- 
tion hypothesis, it is assumed that $\operatorname{det} B$ satisfies the relation

$$
\begin{gathered}
|\operatorname{det} B| \geqq \prod_{j<k}\left(\left|b_{i j}\right|-r_{j}^{\prime}+R_{j}^{\prime}\right) \cdot\left|b_{k+1, k+1}\right| \\
\cdot \prod_{j>k+1}\left(\left|b_{j j}\right|-l_{j}^{\prime}+L_{j}^{\prime}\right),
\end{gathered}
$$

where $R_{j}^{\prime}, L_{j}^{\prime}$ are non-negative, and $r_{j}^{\prime}, l_{j}^{\prime}$ are defined by the relations

$$
r_{j}^{\prime}=\sum_{t>j ; t \neq k} \sigma_{t}\left|b_{j t}\right|, \quad l_{j}^{\prime}=\sum_{k<t<j} \sigma_{t}\left|b_{j t}\right| .
$$

The theorem follows from a set of three estimates, which are established below by applying Lemma 1 . The first estimate is that provided by the relations

$$
\begin{aligned}
\left|b_{k+1, k+1}\right| & \geqq\left|a_{k+1, k+1}\right|-\left|a_{k+1, k}\right|\left(\sigma_{k}\left|a_{k k}\right|-\sum_{t \neq k, k+1}\left|a_{k t}\right|\right) \\
& =\left|a_{k+1, k+1}\right|-\sigma_{k}\left|a_{k+1, k}\right|+\left|a_{k+1, k} / a_{k k}\right| \sum_{t \neq k, k+1}\left|a_{k t}\right| .
\end{aligned}
$$

The second estimate concerns the factor $\left|b_{j j}\right|-l_{j}^{\prime}$, when $j$ exceeds $k+1$ :

$$
\begin{aligned}
\left|b_{j j}\right|-l_{j}^{\prime} \geqq & \left|a_{i j}\right|-\left|a_{j k} / a_{k k}\right|\left(\sigma_{k}\left|a_{k k}\right|-\sum_{t \neq j, k}\left|a_{k t}\right|\right) \\
& -\sum_{k<t<j} \sigma_{t}\left|b_{j t}\right| \\
\geqq & \left|a_{j i}\right|-\sum_{k \leqq t<j} \sigma_{t}\left|a_{j t}\right|+\left|a_{j k} / a_{k k}\right| \sum_{t \neq j, k}\left|a_{k t}\right| \\
& -\left|a_{j k} / a_{k k}\right| \sum_{k<t<j} \sigma_{t}\left|a_{k t}\right| \\
\geqq & \left|a_{i j}\right|-\sum_{k \leqq t<j} \sigma_{t}\left|a_{j t}\right|+\left|a_{j k} / a_{k k}\right|\left(\sum_{t>i}+\sum_{t<k}\right)\left|a_{k t}\right| .
\end{aligned}
$$

Last, it is necessary to estimate the factor $\left|b_{j j}\right|-r_{j}^{\prime}$ if $j$ is less than $k$ :

$$
\begin{aligned}
\left|b_{j j}\right|-r_{j}^{\prime} \geqq & \left|a_{j j}\right|-\sigma_{k}\left|a_{j k}\right|+\left|a_{j k} / a_{k k}\right| \sum_{t \neq j, k}\left|a_{k t}\right|-\sum_{j<t ; t \neq k} \sigma_{t}\left|b_{j t}\right| \\
\geqq & \left|a_{j i}\right|-\sum_{j<t} \sigma_{t}\left|a_{j t}\right| \\
& +\left|a_{j k} / a_{k k}\right|\left(\sum_{t \neq j, k}\left|a_{k t}\right|-\sum_{j<t ; t \neq k} \sigma_{t}\left|a_{k t}\right|\right) \\
\geqq & \left|a_{i j}\right|-\sum_{j<t} \sigma_{t}\left|a_{j t}\right|+\left|a_{j k} / a_{k k}\right| \sum_{t<i}\left|a_{k t}\right| .
\end{aligned}
$$


It will be observed that the above inequalities neglect certain terms which if retained would lead to an inequality slightly stronger than that of Theorem 2 .

THEOREM 3. Upper bounds for $|\operatorname{det} A|$ are the expressions obtained by mechanically reversing the four signs,,,,-+-+ which appear on the right side of (2).

\section{REFERENCES}

1a. J. L. Brenner, Une borne pour un déterminant avec diagonale majorante, C.R. Acad. Sci. Paris vol. 238 (1954) pp. 555-556.

b. - Bounds for determinants, Proc. Nat. Acad. Sci. U.S.A. vol. 40 (1954) pp. $452-454$.

2. P. Furtwängler, Sitzungsber. Akad. Wiss. Wien IIa vol. 145 (1936) pp. 527-528.

3. J. Hadamard, Leçons sur la propagation des ondes, Paris, 1903.

4. Emilie V. Haynsworth, Bounds for determinants with dominant main diagonal, Duke Math. J. vol. 20 (1953) pp. 199-209.

5. A. M. Ostrowski, Note on bounds for determinants with dominant principal diagonal, Proc. Amer. Math. Soc. vol. 3 (1952) pp. 26-30.

6. G. B. Price, Bounds for determinants with dominant principal diagonal, Proc. Amer. Math. Soc. vol. 2 (1951) pp. 497-502.

7. Y. K. Wong, An inequality for Minkowski matrices, Proc. Amer. Math. Soc. vol. 4 (1953) pp. 137-141.

State College of Washington 